\title{
The Science of Data, Data Science: Perversions and Possibilities in the Anthropocene Through a Spatial Justice Lens
}

\section{Travis Weiland}

Statistics often dubbed the science of data (Davidian \& Louis, 2012), and data science, the supposed new revolutionary frontier tasked with breaking the bonds of statistics, both have epistemological roots in exploring datadata being numbers in context (Cobb \& Moore, 1997). I am a mathematics educator that dabbles in science education through my research focus of statistics education. The inductive investigation of data about our world is the common bond between the different communities/disciplines that I work in, which allows me to move fluidly between mathematics and science education. I love exploring data, particularly data related to sociopolitical issues and education. Exploring data never ceases to excite me when I use it to explore issues in my life, to make sense of things I read and see in the media, or in teaching how to use it to others. Looking at the historical roots of investigating data, we can see the practice of statistics having positive impacts on society, such as Florence Nightingale's work with using data visualizations to convey a statistical argument. Nightingale's now famous polar chart entitled, "Diagram of the Causes of Mortality of the Army in the East," illustrates that the vast majority of deaths in the army were from contagious and infectious disease and were often preventable. Because of this data-based argument, Nightingale is often lauded for influencing vast improvements of sanitary conditions at the time. From Nightingale's story and others in society, we can see why statistics has often been portrayed as a powerful practice that can help society make wise decisions and improve our general conditions and state.

T. Weiland $(\varangle)$

University of Houston, Houston, TX, USA

(C) The Author(s) 2022

183

M. F.G. Wallace et al. (eds.), Reimagining Science Education

in the Anthropocene, Palgrave Studies in Education and the Environment, https://doi.org/10.1007/978-3-030-79622-8_11 
We can also see that the practice of statistics has downright devastating impacts and creates perverse realities. For example, Cathy O'Neil (2016) dubbed the term Weapons of Math Destruction (WMDs) in her book by the same name when she discusses how mathematical and statistical models can create unjust structures. What she is referring to as WMDs are actually statistical and mathematical models developed using data to create "objective" algorithms for decision-making. However, the practice of statistics is not neutral or objective. Statistics is a social construct or discourse that selfperpetuates, privileging certain perspectives while silencing others. O'Neil points out there are serious issues with what models create in terms of the realities they create. She describes some of the characteristics of WMDs: "they're opaque, unquestioned, and unaccountable and they operate at a scale to sort, target, or 'optimize' millions of people. By confusing their findings with onthe-ground reality, most of them create pernicious WMD feedback loops" (p. 12). O'Neil goes on to provide examples such as financial models responsible for the crisis in 2008 and the use of value-added models (VAMs) in personnel decisions (e.g., in teacher evaluation systems). What O'Neil and others in the past have brought up is the issue that statistical and mathematical models are not objective. Models are subjective, and they can be a significant influence in shaping the reality we experience. Furthermore, their influence is at scales not considered possible before big data and data science hit the scene. Even the American Statistical Association weighed in on such issues, arguing that VAMs were not designed to inform personnel decisions and should not be used in education - particularly not as mechanisms for teacher evaluationother than to help give some sense of what is occurring overall in a school or district (American Statistical Association, 2014). In other words, statistics and data science, and modeling data, are not our great saviors.

Creating a model is a political act. The modeler decides what variables to consider and what weight or influence they have over the model. In statistics, the goals of models are often explanatory or predictive. In other words, we want models to help explain our reality or predict our future realities. The person creating the model has a direct say over what factors will be used to explain or predict our reality. That can be highly problematic because, as educational researchers know, context matters, and people's lived experiences make a difference in how people experience reality. In other words, models are a discourse that shape reality and form regimes of truth. They are also not inherently good or evil; they merely create things. The discursive formations of such discourses, however, can create structures of injustice that privilege some while disadvantaging others (Foucault, 1972). It is such discursive formations that we need to interrogate when thinking about statistics and data science in the Anthropocene.

In the Anthropocene statistics, data science and mathematical models have become a perversion of reality that society has largely chosen to ignore. Data science is embraced as a great savior because people often view numbers as objective purveyors of truth. However, numbers do not interpret themselves, 
and they do not tell their own story; people do that in all their subjective glory. In this chapter, I will first make some connections between the Anthropocene, in particular the Orbis Spike dating of its beginning, and the human events of that time (Lewis \& Maslin, 2015), to statistics and data science, specifically through the context of spatial data. From this discussion, there are two main points I want to elaborate on and then connect to education. The first is that there is a dialectic tension involved in spatial data enquiry between creating new realities using spatial data and using spatial data to make sense of our reality. You might even argue that this is a never-ending cycle. The second point is that people can choose how to investigate and use spatial data based on their ethics. I believe students should have opportunities to investigate and use spatial statistics both to learn about the world around them and to shape the world around them and that they should learn to do so through considering counter-mapping and spatial justice.

\section{The Anthropocene, Spatial Reality, Maps, and Death}

The Anthropocene is the geological epoch we are currently in, defined by the influence of humans on the geology of the earth (Crutzen \& Stoermer, 2000; Lewis \& Maslin, 2015). Many different starting points for this era have been proposed, including the advent of the steam engine, the invention of nitrogen fixing for fertilizer, the height of nuclear bomb testing, and the Industrial Revolution, just to name a few. I choose to use the date of 1610, drawing from the work of Lewis and Maslin (2015) in their identification of the Orbis Spike. As Davis and Todd (2017) discuss, the choosing of a starting date for the Anthropocene is a political decision with significant implications. The Orbis Spike was the time when $\mathrm{CO}_{2}$ reached historic low levels during the period that Europeans were colonizing America. The drop in $\mathrm{CO}_{2}$ levels is attributed to the significant population drop of Indigenous peoples, as Lewis and Maslin (2015) describe,

Regional population estimates sum to a total of 54 million people in the Americas in 1492, with recent population modelling estimates of 61 million people. Numbers rapidly declined to a minimum of about 6 million people by 1650 via exposure to diseases carried by Europeans, plus war, enslavement and famine. (p. 175)

The change in population described is astonishing in a remarkably depressing way. The connection between this genocide and the dip in $\mathrm{CO}_{2}$ levels globally make a powerful, data-based argument for the Orbis Spike, representing the starting point of a human-driven geological epoch. Using this data also has significant implications, as Lewis and Maslin (2015) discuss:

The Orbis spike implies that colonialism, global trade and coal brought about the Anthropocene. Broadly, this highlights social concerns, particularly the 
unequal power relationships between different groups of people, economic growth, the impacts of globalized trade, and our current reliance on fossil fuels. (p. 177)

The Orbis Spike highlights power relations between peoples and their impact on the natural world. It also makes explicit the insidiousness of colonialism and its influence on the world. Davis and Todd also discuss the implications of the Orbis Spike, "the naming of the Anthropocene epoch and its start date have implications not just for how we understand the world, but this understanding will have material consequences, consequences that affect bodies and land" (p. 767).

The connection of bodies and land that Davis and Todd (2017) make is an important one. This connection highlights the importance of considering a spatial dimension of reality along with historical and social dimensions (Soja, 2010). Soja (2010), who is an urban planner, discusses the importance of a triple dialectic ontology, where space is not treated as just an empty container, but as an integral dimension of reality that is shaped by and shapes the social and historical dimensions. Connecting back to the notion of body and land, Soja considers both to be part of the spatial, "two extremes, the corporeal body and the physical planet, usefully define the outer limits of the concept of spatial (in)justice and the struggles over geography" (p. 31). I bring up Soja's work not so much to focus on his perspective on ontology, but to consider the notion of spatial justice he formulates in the context of its importance in geography and urban planning and connect to issues of justice and the Anthropocene. To illustrate this connection, consider the example of water issues of the American West. Cities like Los Angeles could not exist if it were not for people changing the physical landscape, which did not naturally have the amount of water needed to support the number of people choosing to inhabit the region. To solve this problem they began building a system of diversions, dams, reservoirs, and pipes to take water from the Rocky Mountains, where there was more water. Consequently, the Colorado River now no longer reaches the Pacific Ocean in Mexico. The movement of water is a necessary aspect of urban planning, and we can see the Anthropocene embodied in this example, as the movement of rivers is a major source of geological change, and in this example people have changed the course of the geology of the Colorado River Basin. This example also points to issues of injustice, as the country of Mexico has been deprived of a fresh water source due to people's usage upstream. Furthermore, the change of the flow of the river has changed entire ecosystems and deprived non-human life forms of their habitat.

Geography has consequences. People, however, are capable of interrogating inequities in what geography creates and have agency to change them, as Soja (2010) describes, “their [human geographies'] changeability is crucial, for it makes our geographies the targets for social and political action seeking justice and democratic human rights by increasing their positive and/or negative effects on our lives and livelihoods" (p. 104). It is from this agency that 
spatial justice holds potential for educational endeavors in creating opportunities for students to interrogate issues of spatial justice and perhaps advocate for transformation. I am choosing to draw from these ideas because they have been taken up in mathematics/statistics education by some scholars (Rubel et al., 2017; Rubel, Hall-Wieckert, et al., 2016; Rubel, Lim, et al., 2016), and I seek to continue to work in the direction they have started. Before I delve into the educational side of this chapter though I want to consider one more example. This time I will relate the notion of models and statistics by considering an example related to one of the most common types of models we consider in spatial statistical analyses, maps, which also relate geography to colonialism and the movement of people that helped cause the Orbis Spike, defining the beginning of the Anthropocene.

Explorers/exploiters in the middle of the last millennium were driven by the desire to learn what was over the horizon and by the greed of what that knowledge would be worth in terms of new trade routes and goods. Imagined geographies impact peoples, societies, and science. As Livingston (2003), points out, fantasies of exotic lands and new peoples made imperialist exploration of the "New World" "at once a moral, an economic, and a scientific event. Much of the early history of this transatlantic engagement depended on Europe's geographical fantasies about the Western Hemisphere" (pp. 8-9). By traversing and measuring these uncharted spaces, Western exploiters gained a better understanding of their world but also created their own images of that world, which they also shared on maps.

To bring ideas full circle let me now connect this discussion back to models and statistics and data science. Maps are essentially models of reality, which means they are inherently flawed, as some amount of abstraction must occur to create a model. Early Western cartographers set out across western America to map out the land. We can see elements of their subjectivity in what they choose to focus their attention on and what they left out. For example, they had a clear focus on objectively rendering the physical landscape, such as rivers, mountains, and forests; however, what they neglected to map were the people that inhabited those lands (Remy, 2018). If we look at one of the few remaining examples of a map made by an Indigenous mapmaker (see Fig. 11.1), what we can see is that the concerns of this mapmaker were not at all on the rivers or mountains, but on the groups of people and the paths connecting them. As a mathematics educator, I also cannot help but see the connection to graph theory here where the distance between the nodes (villages) is not important, but what is, are the connections (paths). The emergence of the reasoning behind graph theory is often attributed to the white European mathematician Leonhard Euler; however, it would be an interesting investigation to see if Indigenous cultures actually came up with the reasoning much earlier.

Now consider the map in Fig. 11.2, which shows the tribes of the same area depicted in the deerskin map except overlaid on a common western map of the Carolinas. One of the powers of modern technology is the ability to consider different layers of graphs. For example, consider Google Earth. The 


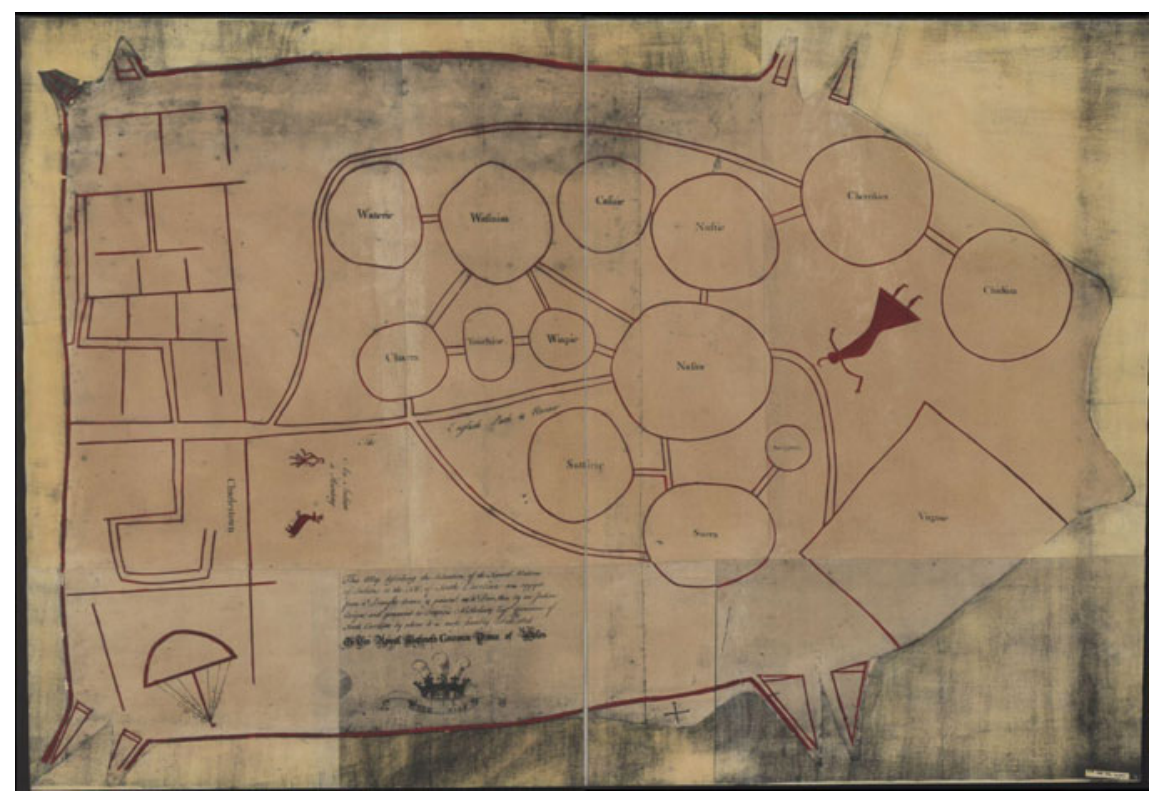

Fig. 11.1 Catawba deerskin map (Source Library of Congress, https://www.loc. gov/resource/g3860.ct000734/)

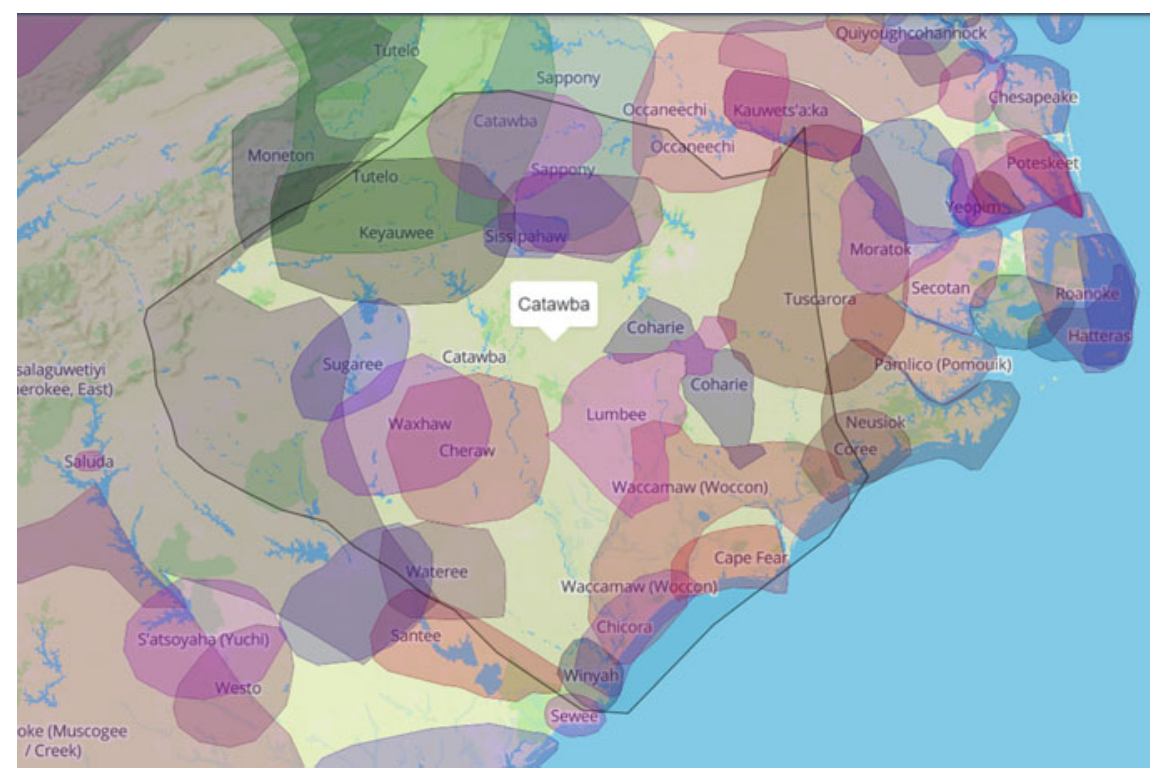

Fig. 11.2 Modern digital mapping of Catawba tribal lands (Source native-lands.ca) 
user can choose to focus on roads, cities, and political boundaries or they can switch to a satellite view where the user can see a bird's-eye view of the same area. In some cases, the user could also switch to a $3 \mathrm{D}$ view to look at the human topography of an area. Hand-drawn maps have inherent constraints in that there is only so much information that can be meaningfully included in the finite space of the map. Early mapmakers chose to use that limited space for conveying the information they found important.

\section{Maps Form Reality in (UN)JUSt Ways}

Now let us think about early mapping endeavors with my first point in mind, which is that there is a dialectic tension involved in spatial data enquiry between creating new realities using spatial data and using spatial data to better understand our reality. If we think of Lewis and Clark's work of mapping the West in North America, they undertook the endeavor to learn more about what was west and how to traverse that space. In other words, they wanted to understand their reality. However, by creating maps that focused only on open physical spaces and ignoring the inhabitants that were already in those spaces, namely Indigenous peoples who had lived there for centuries, they created the "reality" that the west was this vast, uninhabited open space ready to be conquered and owned. The reality created helped fuel the western expansion movement that later occurred and, in turn, the gradual process of dislocating and killing of Indigenous peoples that lived on those lands. We do not know that this was the intention of Lewis and Clark, but it is undeniable that people used their models in such ways and facilitated westward expansion. How we create and how we use models matters and it is a political act.

Now to my second point, which is that people can choose how to investigate and use spatial data based on their ethics. A good example of this point is gerrymandering, which is a hot topic in politics in the United States and intersects with statistics (Honner \& Gonchar, 2017; Klarreich, 2017). Gerrymandering is when a political group draws the boundaries for voting districts with their own political interests in mind to disadvantage another group. The state I am writing this in is a prime example, North Carolina. In the most recent election in 2018, Democrats in North Carolina earned 48.3 percent of the total vote cast in House races, but only won three seats. On the other hand, Republicans had 50.4 percent of the vote and won nine seats. The inequities can be seen in spatial graphics in the New York Times article by Astor and Lai (2018), entitled "What's Stronger Than a Blue Wave? Gerrymandered Districts." You might ask how such a system of injustice could have been allowed to be created. It all happened when Republican politicians gained control of the governorship, Senate, and House of North Carolina in the 2010 elections, which coincided with the decennial census that is used in the U.S. to draw political boundaries in a "representative" fashion. We also have a new use of technology employed in redrawing the lines, namely GIS. Using demographic data from the census and voter registration databases, the Republican 
Party in North Carolina that was in power was able to use this data to create spatial boundaries that favored them. This is an example of how data can be used in unjust ways to create a new reality with spatial models, namely the political power balance based on voting district lines. The issue of gerrymandering is at the center of the current issue around the 45th president of the United States attempting to illegally add a question about citizenship to the 2020 census form, which has been struck down by the courts. This is an example of the use of spatial data based on the ethic of capitalism, greed, and power lust. Later on, I will show an example of how a justice-oriented ethic can create different possibilities.

So how does spatial justice relate to the two points I have made? It relates in that it can be used as an ethic in balancing between better understanding one's realities through spatial data and creating a new reality through spatial data and models. For example, counter-mapping is a strategy that has been taken up by Indigenous groups for several decades now, as described by Remy (2018), to interrogate and trouble common Western maps' narratives. Remy goes on to state: "The development and democratising of the access to digital technologies and online mapping systems opens the possibility for the growth of Indigenous counter-mapping projects and their complete ownership by the community." The idea of counter-mapping draws from the notion of using the master's tools. A similar notion has been put forth by the mathematics education researcher Rochelle Guitiérrez (2016), where she describes using the master's tools as one of the strategies for what she refers to as creative insubordination in mathematics teaching. Drawing from these perspectives, I argue we should be teaching about space and spatial ways of knowing in mathematics classes. With new digital mapping tools and big data, there has been a democratization of access to opportunities to investigate spatial issues that we have never seen before, and it is accessible to not only teachers but students as well.

\section{Spatial Justice in Mathematics/Statistics Education}

To start with, I would like to draw from a notion from Marilyn Frankenstein who is arguably one of the first people to consider looking at statistics education through a critical lens. Frankenstein (1994) discusses her goal in teaching to outrage students at the utter ridiculousness of things happening around us through interrogating quantities. For example, let's go back and consider the change in populations of Indigenous people from estimates of 61 million people in 1492 to a minimum of about 6 million people by 1650 (Lewis \& Maslin, 2015). That is a 90\% decrease in Indigenous peoples in just over 150 years. That is outrageous and helps to highlight the importance of considering such statistics and creating opportunities for students to experience them.

The idea of considering spatial justice in mathematics or statistics education is quite new, with only a handful of scholars investigating the intersection. 
The social and historical dimensions of reality have long been important when considering the teaching and learning of mathematics in the social turn (Lerman, 2000), and more recently political dimensions have been highlighted in the sociopolitical turn (Gutiérrez, 2013). Soja (2010) discussed the spatial turn in his work and more recently Larnell and Bullock (2018) created a sociospatial framework for urban mathematics education, claiming a spatial turn in mathematics education. A recent push in investigating the intersection of mathematics education and spatial justice has been spearheaded by Dr. Laurie Rubel and her team in their work on conceptualizing Teaching Mathematics for Spatial Justice (TMSpJ); (Rubel, 2017; Rubel, Hall-Wieckert, et al., 2016; Rubel, Lim, et al., 2016). In their work, they developed and implemented lessons involving spatial justice themes enacted with critical pedagogy. Their work was situated in a mathematics course in high school and undergraduate classes serving predominantly underserved students in New York City (Rubel, Lim, et al., 2016). In their work, they describe their design heuristic for TMSpJ that included three main considerations: make race explicit, reading the world, and writing the world - the last two considerations coming from Paulo Freire's work on critical literacy and reading and writing the word and the world. With this design heuristic in mind and the points I have made up to this point, I will now show an example of how they can all be incorporated into the classroom through teaching the science of data.

\section{Spatial Justice and Data in the Context of Charlotte, North Carolina}

The city of Charlotte, North Carolina, has a history of redlining, particularly after the Civil War. In an attempt to make the city more equitable in the future, the city has undertaken an initiative they refer to as Charlotte 2040 , where they are seeking to create a more equitable city by the year 2040. Figure 3 shows how strongly the practice of redlining influenced where people of different races were able to live in the city. The spatial depiction of housing and race data in Fig. 11.3 is part of the Charlotte 2040s interactive slide show to show the issue of housing inequity in Charlotte and is publicly available for people to use. This could serve as a starting point for bringing the notion of spatial injustice and data into a class. This topic has potential for cross-disciplinary connections as well, particularly in terms of connecting social studies to mathematics, talking about the historical context that created such injustices and using statistics and data to highlight such inequities. There are also connections to sciences when you begin considering environmental factors. For example, in the areas where there is a greater density of Black residents, we can see from the data in Fig. 11.4 there is also a higher level of environmental exposure risk, particularly near the airport. There are also possibilities for citizen science in this context, perhaps looking 

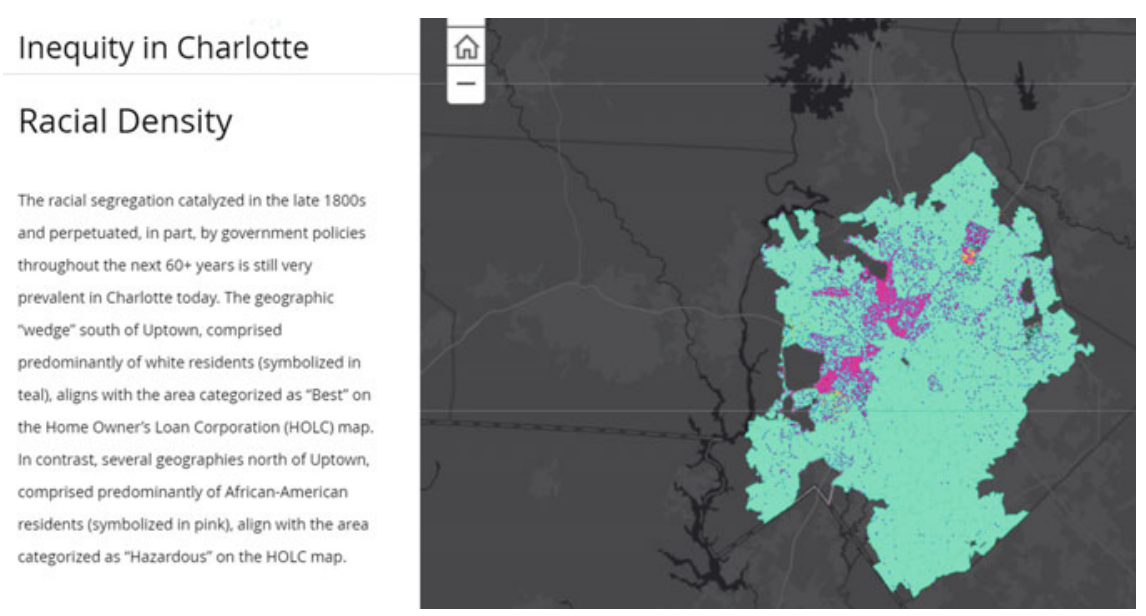

Fig. 11.3 Racial density map where each point represents one person and the points are colored based on the race of the person. The light colored dots represent white residents and the darker dots represent non-white, in this case predominantly Black, residents (Source https://charlotte.maps.arcgis.com/apps/MapJournal/index. html?appid=0715a3477e484feb9ffc0b9ce88el5d2)

at water quality; measuring soil samples, temperature, air quality, or other environmental factors; and geotagging the data collected to then create spatial representations of the data.

There is also potential to bring issues of spatial injustice across disciplinary lines and into the teacher education curriculum. For example, look at Figs. 11.5, 11.6, and 11.7 that show an interactive data visualization of the multivariate relationship between location, educational attainment, and unemployment rate. You can also notice from these maps that if you compare them to the racial density map in Fig. 11.3 there is a pattern between location, educational attainment, unemployment, rate, and the race of people living in those areas. These types of data visuals can help to show the complex interaction of many different factors that influence and are influenced by education systems and structures of injustice. It is well known that injustices in the educational system are very space based (Kozol, 1991). Furthermore, redlining has caused segregation in schools because school attendance is based on where people live, and the quality of schools is often based on the tax base there. There are also other websites that can be explored that show locations of schools, which could then be considered in regards to the other spatial representations of data. School performance data is also often linked to the factors discussed already. All of this data and the spatial representations of it help to highlight the importance of space in shaping the reality that we experience. 
Fig. 11.4 Spatial data map of environmental exposure risk factors in the city of Charlotte (City of Charlotte, 2019). Note $<1$ is a normal, acceptable risk of non-cancer adverse health effects, $>1$ is likely to increase risk of non-cancer adverse health effects

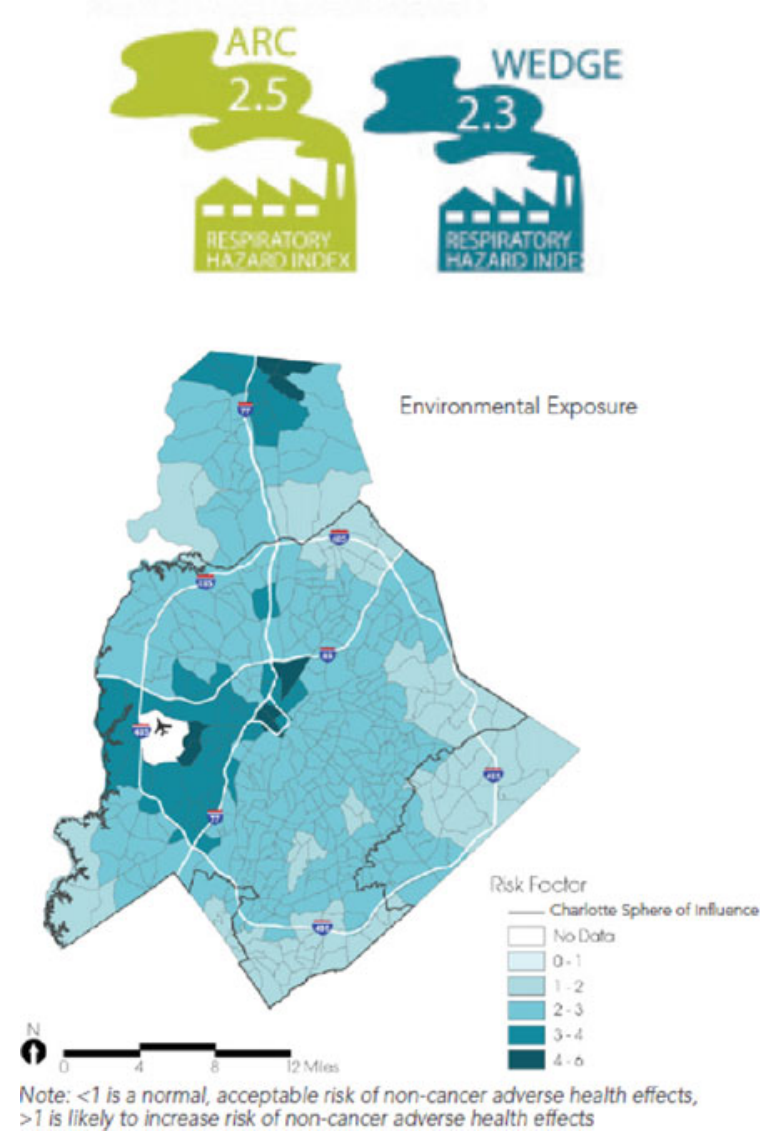

\section{Discussion}

My goal in this piece was to try to make some connections between the Anthropocene, science education, statistics and data science education, and issues of spatial justice. I believe there is great potential here to bring new ways of interrogating injustices into not only school classrooms but also teacher education as I tried to briefly highlight in the example of exploring equity in Charlotte. The Charlotte 2040 plan is ambitious and one of the most transparent and significant I have seen to try to transform a community into a more equitable space. However, there is some irony in this plan as well. To bring in one more connection, if you look at Fig. 11.8, you will see a visualization of what Indigenous groups are known to have inhabited the lands where Charlotte is today. The irony of Charlotte's plan is that before redlining was an issue, in fact well before there were inhabitants of European and African ancestry inhabiting the area, there were already many Indigenous peoples that 


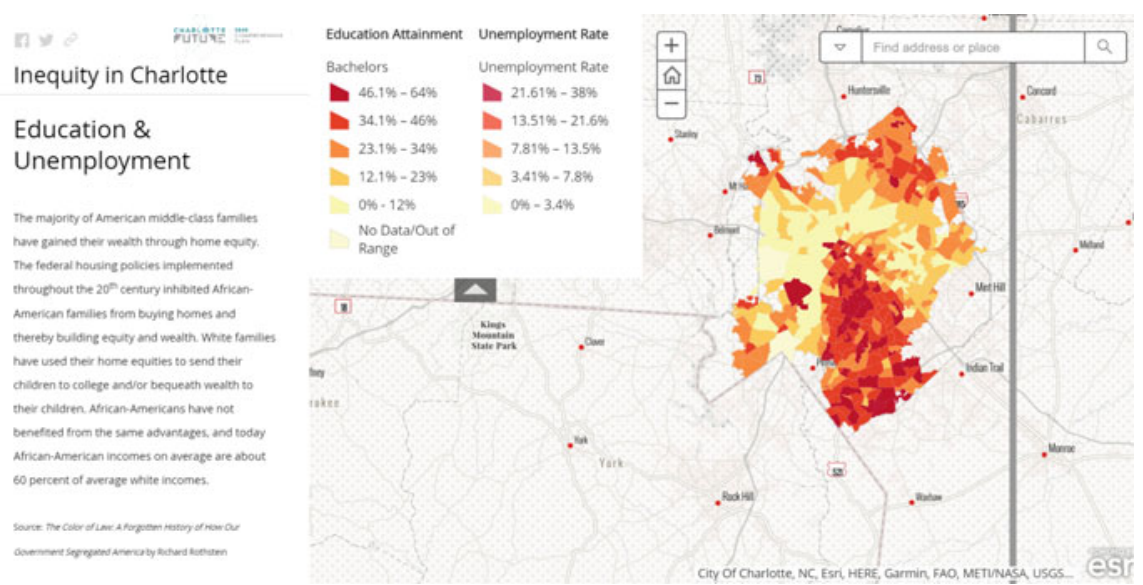

Fig. 11.5 Map of Charlotte region with the graph colored based on the scale on the left for Education Attainment. The vertical bar on the right of the map can be slid across the graph to change the color-coding of the data represented in the graph (Source https://charlotte.maps.arcgis.com/apps/MapJournal/index.html? appid=0715a3477e484feb9ffc0b9ce88el5d2)

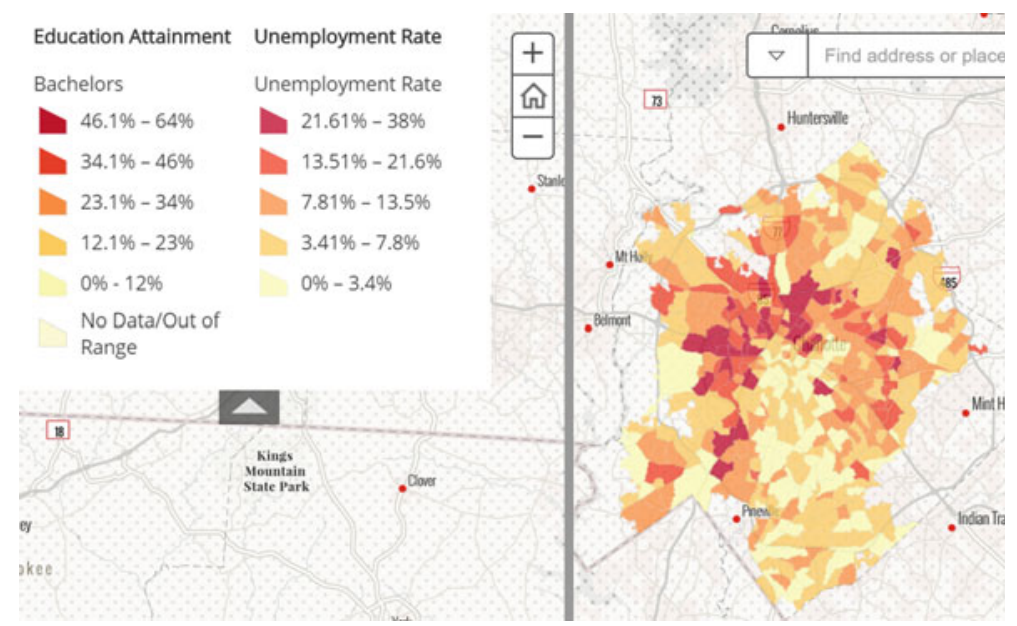

Fig. 11.6 Map of Charlotte region with the graph colored based on the scale on the right for unemployment Rate. The vertical bar on the left of the map can be slid across the graph to change the color-coding of the data represented in the graph (Source https://charlotte.maps.arcgis.com/apps/MapJournal/index.html? appid=0715a3477e484feb9ffc0b9ce88el5d2) 


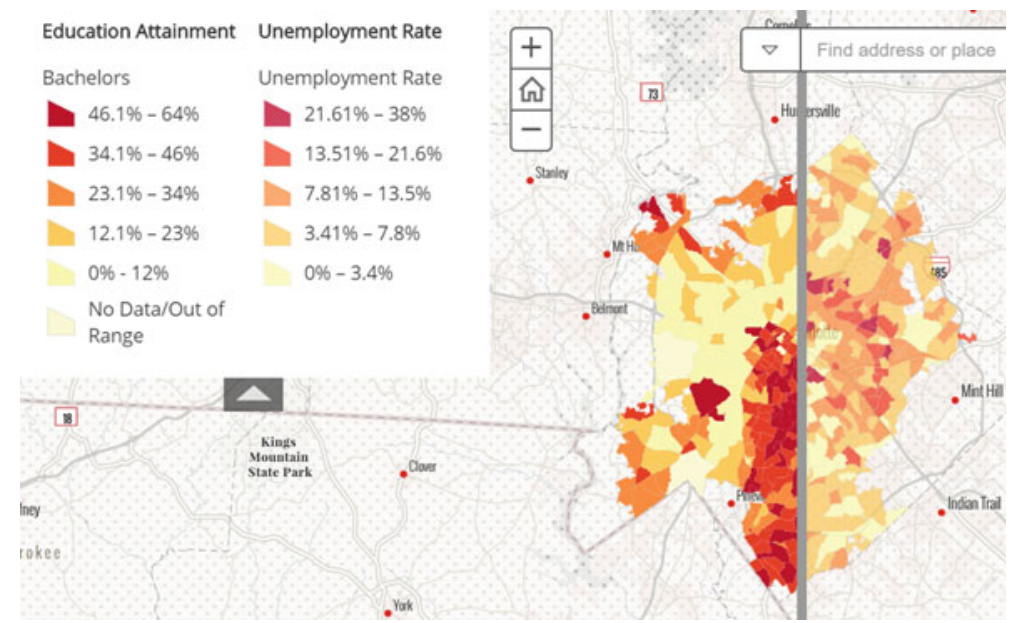

Fig. 11.7 Map of Charlotte region. The vertical bar in the middle of the map can be slid across the graph to change the color-coding of the data represented in the graph with the left side of the bar representing Education Attainment and the right side Unemployment Rate (Source https://charlotte.maps.arcgis.com/apps/Map Journal/index.html?appid=0715a3477e484feb9ffc0b9ce88el5d2)
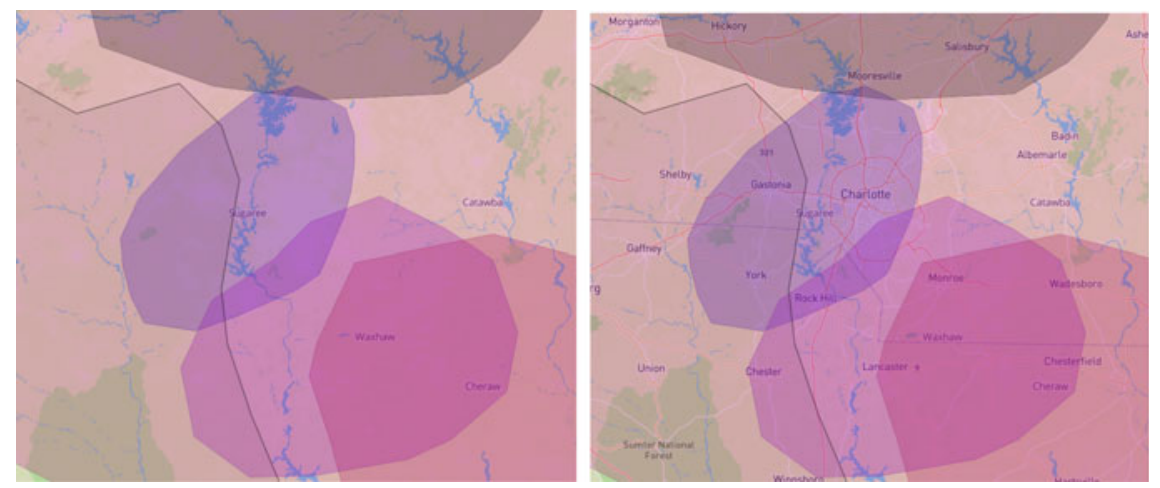

Fig. 11.8 Side-by-side maps of the Charlotte region showing the tribes that inhabited the land on the left and on the right those tribe's lands with labels of the current cities (Source https://native-land.ca/)

inhabited the area. Where is the justice for Indigenous peoples in Charlotte's plan? Can spatial justice for all ever truly be realized, or is it a pipe dream?

I would also like to point out the current issues of spatial injustice unfolding in the world in relation to the global pandemic of COVID-19. In the context of the U.S., different states enact different policies toward inhibiting the spread of the coronavirus that at the time I am writing this is responsible for more than 550,000 deaths in my country. Such artificial spatial boundaries then 
determine where conditions are ripe for the spread of the virus and open travel allows for such policies to impact people across those artificial boundaries. Viruses do not know or respect politics. There are connections between this currently unfolding crisis and the themes discussed in this chapter. A prime example is the case of Brazil, which currently is run by a right-wing president, who denies the dangers of the virus even against his own health advisors' advice, and focuses on capitalistic endeavors by working to focus on the economy rather than saving lives.

Much of the data is visualized spatially. Take, for example, maps of cases per capita in Brazil by the New York Times (https://www.nytimes. $\mathrm{com} /$ interactive/2020/world/americas/brazil-coronavirus-cases.html) that is updated daily. The map shows that the highest ratios of cases per capita are all in the more rural states in northern Brazil, which are also the locations of many of Brazil's Indigenous peoples. Such examples can also be seen across the Americas, including in Canada and the U.S. (Haig, 2020; Lawrimore, 2020). These are just more examples of capitalist and colonialist ethics leading to the death of Indigenous peoples and how spatial data help investigate such issues.

\section{REFLECTIONS}

Before ending the discussion, I have a reflection that I believe important to share. I believe it is important for an author to position oneself in their work so the reader can have that information to see how the work is shaped by the author's subjectivity. I see each piece I write as a learning experience as much as it is a form of sharing my own understanding with others. Writing this piece pushed me in several ways and uncovered some tensions in my work that I need to deal with in the future. I typically work at the intersection of mathematics education, statistics education, critical literacy, statistical literacy, and the learning sciences. When Jesse Bazzul asked me if I would be interested in writing a piece in this book, I jumped at the opportunity to push myself and play with new ideas. Playing with new ideas also challenges old ones. Though the Anthropocene is well known in science and science education communities, it has not infiltrated the fields that I generally work in. Furthermore, being a scholar from the United States, I have come across work from Indigenous scholars and seen some educators incorporate it into their work, but still very minimally so, especially when compared to scholars from Canada with whom I have worked. In digging into readings to help me think about what I was going to write for this chapter, I started with one idea. That idea, however, changed significantly over the course of my playing with ideas. Honestly, I ended in great conflict and almost decided to scrap the whole thing and bow out of the endeavor.

Where my greatest conflict came in was in the consideration of who I was citing in my work. In my academic preparation, I was introduced to the notion that who you cite is a political act, and I have tried to always take that to heart in my writing. The conflict I encountered in writing this piece was that 
though the line of thinking that began to emerge from my reading and the shift in my ideas revolved around reading about Lewis and Maslin's (2015) work, deciding on a date for the beginning of the Anthropocene, and deciding about 1610 because it had both scientific and cultural implications, this was an entirely new concept to me, especially when I was confronted with the quantities they presented for Indigenous populations before and then a century after European conquistadors and settlers arrived. This started me down the path of connecting ideas between the intersection of statistics and spatial justice issues. I had started with the notion of mapping, and how you use the information you gain from data and spatial analyses has implications and can produce systems of oppression and injustice. After having written the chapter in this new line of thinking, what I realized upon reflection and review was that the vast majority of the scholars I was citing were white males. I was discussing the use of the date of the Orbis Spike as an important political act because of how it highlights the devastation brought on by colonization, yet there were likely Indigenous scholars and Indigenous ways of knowing that could be used to speak to these ideas and help to view them through a different lens. I have chosen to still submit this work because the scholars I cite are the sources for where my current ideas as they are come from. Yet, this chapter and reflection serve as a challenge for myself to learn more about the work of Indigenous scholars and ways of knowing. I challenge myself in the future as I continue to write on these ideas to do so from a more diverse array of perspectives, especially those that have been historically marginalized.

\section{REFERENCES}

American Statistical Association. (2014). ASA statement on using value-added models for educational assessment. https://www.amstat.org/policy/pdfs/ASA_VAM_Sta tement.pdf.

Astor, M., \& Lai, K. K. R. (2018, November 29). What's stronger than a blue wave? Gerrymandered districts. The New York Times. https://www.nytimes.com/int eractive/2018/11/29/us/politics/north-carolina-gerrymandering.html, https:// www.nytimes.com/interactive/2018/11/29/us/politics/north-carolina-gerrymand ering.html.

City of Charlotte. (2019). Charlotte Future 2040 Comprehensive Plan: Built City Equity Atlas. http://ww.charmeck.org/Planning/CompPlan/Charlotte_Equ ity_Atlas.pdf.

Cobb, G. W., \& Moore, D. S. (1997). Mathematics, statistics, and teaching. The American Mathematical Monthly, 104(9), 801-823.

Crutzen, P. J., \& Stoermer, E. F. (2000). The “Anthropocene." Global Change Newsletter, 41, 17-18.

Davidian, M., \& Louis, T. A. (2012). Why statistics? Science, 336(6077), 12. https:// doi.org/10.1126/science.1218685.

Davis, H., \& Todd, Z. (2017). On the importance of a date, or decolonizing the Anthropocene. ACME: An International Journal for Critical Geographies, 16(4), 761-780. 
Foucault, M. (1972). The archaeology of knowledge and the discourse of language. Pantheon Books.

Frankenstein, M. (1994). Understanding the politics of mathematical knowledge as an integral part of becoming critically numerate. Radical Statistics, 56, 22-40.

Gutierrez, R. (2013). The sociopolitical turn in mathematics education. Journal for Research in Mathematics Education, 44(1), 37-68.

Gutiérrez, R. (2016). Strategies for creative insubordination in mathematics teaching. Teaching for Excellence and Equity in Mathematics, 7(1), 52-60.

Haig, T. (2020). First Nations leaders in northern Canada warn of COVID-19 time bomb. Radio Canada International. https://www.rcinet.ca/en/2020/03/ 12/first-nations-leaders-in-northern-canada-warn-of-covid-19-time-bomb/.

Honner, P., \& Gonchar, M. (2017, November 30). Investigating gerrymandering and the math behind partisan maps. The New York Times. https://www.nytimes. $\mathrm{com} / 2017 / 11 / 30 /$ learning/lesson-plans/investigating-gerrymandering-and-themath-behind-partisan-maps.html.

Klarreich, E. (2017). The mathematics behind gerrymandering. Quanta Magazine. https://www.quantamagazine.org/the-mathematics-behind-gerrymandering$20170404 /$.

Kozol, J. (1991). Savage inequalities. Harper Perennial.

Larnell, G. V., \& Bullock, E. C. (2018). A socio-spatial framework for urban mathematics education: Considering equity, social justice, and the spatial turn. In T. G. Bartell (Ed.), Toward equity and social justice in mathematics education (pp. 43-57). Springer.

Lawrimore, S. (2020, May 8). The impact of COVID-19 on Native American communities. Harvard Gazette. https://news.harvard.edu/gazette/story/2020/05/theimpact-of-covid-19-on-native-american-communities/.

Lerman, S. (2000). The social turn in mathematics education research. In J. Boaler (Ed.), Multiple perspectives on mathematics teaching and learning (pp. 19-44). Ablex.

Lewis, S. L., \& Maslin, M. A. (2015). Defining the Anthropocene. Nature, 519(7542), 171-180. https://doi.org/https://doi.org/10.1038/nature14258.

Livingston, D. (2003). Putting science in its place: Geographies of scientific knowledge. University of Chicago Press.

O’Neil, C. (2016). Weapons of math destruction. Crown.

Remy, L. (2018, December 6). Making the map speak: Indigenous animated cartographies as contrapuntal spatial representations. NECSUS. https://necsus-ejms.org/ making-the-map-speak-indigenous-animated-cartographies-as-contrapuntal-spatialrepresentations/.

Rubel, L. H., Hall-Wieckert, M., \& Lim, V. Y. (2016). Teaching mathematics for spatial justice: Beyond a victory narrative. Harvard Educational Review, 86(4), 556579.

Rubel, L. H., Hall-Wieckert, M., \& Lim, V. Y. (2017). Making space for place: Mapping tools and practices to teach for spatial justice. Journal of the Learning Sciences, 26(4), 643-687. https://doi.org/https://doi.org/10.1080/10508406. 2017.1336440 .

Rubel, L. H., Lim, V. Y., Hall-Wieckert, M., \& Sullivan, M. (2016). Teaching mathematics for spatial justice: An investigation of the lottery. Cognition and Instruction, 34(1), 1-26. https://doi.org/https://doi.org/10.1080/07370008. 2015.1118691 .

Soja, E. (2010). Seeking spatial justice. University of Minnesota Press. 
Open Access This chapter is licensed under the terms of the Creative Commons Attribution 4.0 International License (http://creativecommons.org/licenses/by/4.0/), which permits use, sharing, adaptation, distribution and reproduction in any medium or format, as long as you give appropriate credit to the original author(s) and the source, provide a link to the Creative Commons license and indicate if changes were made.

The images or other third party material in this chapter are included in the chapter's Creative Commons license, unless indicated otherwise in a credit line to the material. If material is not included in the chapter's Creative Commons license and your intended use is not permitted by statutory regulation or exceeds the permitted use, you will need to obtain permission directly from the copyright holder. 